\title{
Mechanisms of invasion and persistence of infectious agents
}

\author{
Sucharit Bhakdi
}

Received: 30 August 2012/ Accepted: 30 August 2012

(c) Springer-Verlag 2012

The Collaborative Research Center 490 was founded in 2000 and devoted itself over a period of 12 years to the study of cellular and molecular mechanisms underlying invasion and persistence of infectious agents in the host. A broad range of pathogens, all of major medical importance, were studied with two long-term objectives. The first was to expand understanding of processes relevant to infection and immunity towards the pathogen. The second was to uncover common themes and principles governing the biology of such diverse agents as bacterial toxins, viruses and protozoan parasites. The collection of papers by members of the CRC presented at its Closing Symposium in March 2012 attests to the success of the venture. Distinguished guest speakers imbued the meeting with a vibrant, exciting atmosphere with their presentations that remain unforgettable. Several guests have been able to make their contributions available for inclusion in this special volume, which brings the CRC 490 to its final close: with a look back and beyond together. 